\title{
Couples' arts participation: assessing individual and joint time use
}

\author{
Elisabetta Lazzaro ${ }^{1} \cdot$ Carlofilippo Frateschi $^{2}$
}

Received: 13 June 2012/Accepted: 9 December 2015/Published online: 29 December 2015

(C) The Author(s) 2015. This article is published with open access at Springerlink.com

\begin{abstract}
In this paper, we analyse the joint and individual time that Italian couples allocate to the different arts activities and arts practices. The Time Use Survey of Italian households (ISTAT 2002-2003) is used for the first time for this purpose. Despite an unbalanced gender division of paid and unpaid work in this country, women are shown to have a greater predisposition towards engaging in the arts. Altogether, Italian couples spend half of their arts time together. After we apply a Heckman's selection model, results show the overall positive effects of age, education, individual and couple's well-being and weekend participation, and the negative effects of children and residence in southern regions. Yet we demonstrate that the likelihood to participate in the arts and the amount of time allocated to them are determined by different factors. In particular, we highlight some differences and complementarities in partners' personal and mutual influence and respective roles within the couple and the household.
\end{abstract}

Keywords Arts participation - Time use - Social interactions $\cdot$ Heckman's sample selection model

JEL Classification Z11 $\cdot \mathrm{D} 1 \cdot \mathrm{I} 31 \cdot \mathrm{J} 22$

Elisabetta Lazzaro

elisabetta.lazzaro@hku.nl

Carlofilippo Frateschi

carlo.frateschi@unipd.it

1 Department of Creative Economy, HKU University of the Arts Utrecht, Lange Viestraat 2b, Postbus 1520, 3500 BM Utrecht, The Netherlands

2 Department of Economics, University of Padua, Via del Santo 33, 35123 Padua, Italy 


\section{Introduction}

Arts participation is a complex activity determined by a combination of factors, including economic ones, personal cultural capital and social capital. In particular, arts participation can take place in interaction with other individuals, who can enrich such an experience.

Time is becoming an increasingly precious resource, one that shapes our lives. The amount of time allocated to arts activities - whether attending arts events or engaging in amateur art practices - can indicate how much individuals value the arts, and add to other measurements of arts demand, such as money spent, stated preferences, and retrospective surveys on participation.

This paper sheds light on these different aspects by focusing on one fundamental social unit - couples — and by considering the joint arts participation of spouses. We will examine not only the probability of their participating in the arts but also the factors that determine the amount of time couples dedicate to the arts and how partners may influence each other. The country under consideration-Italy-is distinguished not only by an extremely rich cultural supply but also by striking gender inequalities in terms of paid and unpaid work distribution between spouses. This has repercussions on both the free and discretionary time, in which arts participation could take place.

In our analysis, we apply a household production framework, where a combination of goods and time contribute to such a production. In this study, diary data drawn from the national Time Use Survey of Italian households (ISTAT 2002-2003) will be used for the first time to study arts participation. We will also distinguish between arts attendance (visiting a theatre, a museum, a concert, etc.) and amateur arts practices (playing music, painting, dancing, etc.).

In the next section, we contextualise our study in the literature on couples' leisure and arts participation, including contributions based on diary data. Section 3 describes the data set, while Sect. 4 introduces the empirical model and the underlying hypotheses in explaining couples' time use and togetherness in arts participation. In Sect. 5, we present and discuss the empirical results. The final section concludes the paper.

\section{Literature review}

In Becker's (1965) theory of household production, utility is a function of activity, which is produced by combining goods and time. Utility maximisation is subject to the constraints of income (from labour and not from labour) and time. Since the household is assumed to choose freely the amount of time it dedicates to labour, optimisation will consist of a combination of consumption and production. In such a framework, Jenkins and Osberg (2005: 124) identify 'one's spouse' as 'a primary candidate' for joint or social leisure (as opposed to solo leisure). Indeed, this it is also a 'prime reason why people get married in the first place', in addition to more traditional economic advantages based on the joint consumption of material goods and division of labour (Lam 1988). 
In the more specific context of arts participation, Mohr and DiMaggio (1995) have pointed to the important relation between cultural participation and marital selection and the ways in which the former can impact the latter. The inverse relation is also true, and marriage can diminish or increase arts participation of partners as a result of a mutual influence in terms of human capital (Montgomery and Robinson 2010). Joint arts participation can be considered 'such a valuable and rewarding activity' that full-time working partners 'prioritize' joint over individual attendance (Kraaykamp et al. 2008: 328).

Within a couple, individual and joint arts participation can be affected by the other spouse's characteristics and/or decision to participate. Such influence, however, is not necessarily reciprocal or symmetrical. For instance, Upright (2004) highlights gender differences in such influence in American couples. Kraaykamp et al. (2007) have studied how the individual frequency of media use in Dutch couples is the result of both spouses' statuses. Similarly, Konig et al. (2008) have looked at Dutch partners' reciprocal influence on average time spent watching TV. Finally, through a more qualitative-analysis approach, Silva and Le Roux (2011) have stressed different cultural capital and gender patterns in the cultural participation of British couples. ${ }^{1}$

Life in a couple involves interaction, togetherness and coordination, in which the time dimension plays a fundamental role. These aspects have been mainly studied in economics in terms of paid and non-paid work and other occupations of partners based on time use analysis. For instance, Connelly and Kimmel (2009) have examined the relationship between married mothers' and fathers' wages, employment and leisure, child caregiving and home production. Through a multinational study, Gimenez-Nadal and Sevilla-Sanz (2010) have shown that for females an increase in market labour time has not been accompanied by a corresponding decrease in non-market labour time and that this has negative repercussions on their leisure. Jenkins and Osberg (2005) have developed a time use model and provided evidence of how British working partners tend to coordinate in joint leisure.

Italian couples have received less attention in the recent economic literature despite their idiosyncrasy in time allocation and coordination in market and nonmarket work and leisure activities, especially when compared to other European and OECD countries (Mencarini and Tanturri 2004). In particular, Italian wives have the lowest employment rates, and their husbands contribute the least to unpaid housework (Bloemen et al. 2010). If we consider paid and non-paid work together, Italian women work $28 \%$ hours more than men (Beblo 2001). Given that Italy is a country extremely rich in cultural supply, Italian couples represent an interesting case of arts participation and social interactions.

Since the 1970s, diary or time use data have been included in national and international statistics on culture (Horowitz 1981, 1990; Horn 1983). At the same time, there is a growing interest in diary data in general among economists, who study 'the role of time in behavioural models of market and non-market activities' (Juster and Stafford 1991: 472). Today these data are part of national statistics in industrialised and industrialising countries. Time use data are mainly collected

\footnotetext{
1 These studies have been based on retrospective surveys.
} 
through national surveys. On one or more random days, individuals from sampled households are either interviewed or fill in diaries in which they track in detail how they allocate their time to various activities (work, leisure, transportation, personal care, etc.). These diaries, which are completed in real time, are particularly accurate and reliable. The surveys are complemented by socio-demographic data about the interviewees and their households.

While time use analysis is an established research field in economics and the social sciences (e.g. study of work and non-work patterns, work-life balance, etc.), its application to arts participation is relatively recent and still underdeveloped. ${ }^{2}$ Robinson and Godbey (1997) have employed time use analysis to study how Americans use their time and have considered, among other activities, arts participation and its predictors. Van Rees and van Eijck (2003) have examined the impact of status, gender and age on media use in the Netherlands. In her review of cultural consumption research, Katz-Gerro (2004) also considers time use analysis. Corneo (2005) has used a multiple equilibria model based on social leisure to explain the positive correlation between television viewing and working time in OECD countries, and Robinson and Martin (2009) have used time diaries to study the relationship between trends in TV watching and its relation with new technologies and long-term individual happiness. Finally, Katsuura (2008) has studied arts participation in Japan using the Japanese national time use survey (STULA), which has a large sample, distinguishes among many different arts activities and offers possibility of comparing time and probability of participation for the same respondents. This study, however, focuses on the diversity of arts activities and considers simply participation versus non-participation rather than the amount of time spent on each activity.

Following more general contributions on couples' leisure time, in this paper we aim to use the information contained in time use data, by focusing on time use patterns for arts activities and practices and comparing them with participation. The application of time use analysis to arts participation is convenient for at least four reasons. First, time use data are usually collected within one or a few days, enabling a more precise account of a typically rare activity such as arts participation; this reduces the 'memory' bias typical of the retrospective surveys that have traditionally been used to study arts participation. Second, the reduced memory bias also permits a more precise account of the individuals with whom the activities were carried out. This allows us to consider the important factor of socialisation in arts participation and, for the purpose of this paper, to track more accurately spouses' joint participation. Third, even if diary data, unlike retrospective surveys on arts participation, are not specifically collected for the purpose of arts participation analysis, their accuracy makes it possible to distinguish among a variety of arts-related activities, including arts attendance (attending a museum, a theatre, etc.), amateur arts practices and arts lessons in different arts sectors and disciplines (visual arts, performing arts, media, heritage, etc.), as is done in retrospective surveys. Finally, the time allocated to the arts can provide an additional measurement of cultural value.

\footnotetext{
${ }^{2}$ Due to lower frequency of arts activities (Sullivan 2007), which requires large data sets.
} 


\section{Data}

We used data from the Italian national survey 'Use of free time', which was conducted between April 2002 and March 2003. Each household's component completed a diary, which also tracked the synchronisation of activities of the couple within the household. Activities were self-reported by respondents through daily diaries accounting for primary, and, possibly, secondary activities carried out simultaneously. Participants were asked to account for each time slot of $10 \mathrm{~min}$ during the period of the survey. The survey included about 21,075 households and 55,773 individuals. Socio-economic information on the characteristics of households and components was collected through interviews. For privacy reasons, geographical information about respondents was made available either by region and geographical repartition or by the socio-demographic typology of the municipality and the geographical distribution.

After the survey, the daily activities were coded. Their classification typically comprises various work, housework, personal care, sleeping and leisure subcategories, from which we could distinguish a series of passive and active arts activities. In particular, from the Entertainment and Cultural Activities (ISTAT Code 5.2), we selected going to the cinema, the theatre, a concert, a museum, an exhibition, a library (not for study purposes), and cultural or entertainment excursions. Active arts practices, such as classic, modern or jazz dancing, fell within Physical Exercise (ISTAT Code 6.1); Artistic Practices (ISTAT Code 7.1), included, respectively, visual arts, photography, video making, performing arts (theatre, music, etc.), literature (writing fiction, poetry, etc.) and 'other artistic practices'. We also included arts lessons from Non-Formal Education (Code 2.2). We focused on primary activities.

Data made it possible to consider both legally married and de facto cohabiting heterosexual couples, whether employed or not. Paired couples totalled 13,153. In our data set, the closest possible answer to the with-whom question is only generically referred to other household members aged 10 and more. Therefore, this would not allow us to control for specific spouses' joint participation. However, we could observe synchronicity of spouses for each specific activity. Given the degree of detail in which we track the frequency of the couple's arts activities, their relative rarity, and the closeness of their relationship, we assume that synchronous participation is equivalent to joint participation. For instance, if we observe both spouses going to the cinema or to ballet at the same time, it is hard to suppose they went separately. ${ }^{3}$

For each type of arts activity, Table 1 reports the average number of minutes spent by husbands and wives, respectively, during weekdays, on Saturdays, on Sundays and on an average day. The table is completed by the actual number of individuals participating in the arts, their proportion in the sample, and the average time spent on each type of activity. Over the entire sample, less than 5 min are spent

\footnotetext{
3 Contributions on leisure like those of Hallberg (2003), Voorpostel et al. (2009) and Scheffel (2010) distinguish between simultaneity and togetherness. On the other hand, notice that these contributions, unlike this one, consider only very aggregated groups of possible activities overall, such as market work, household work, personal care and leisure.
} 


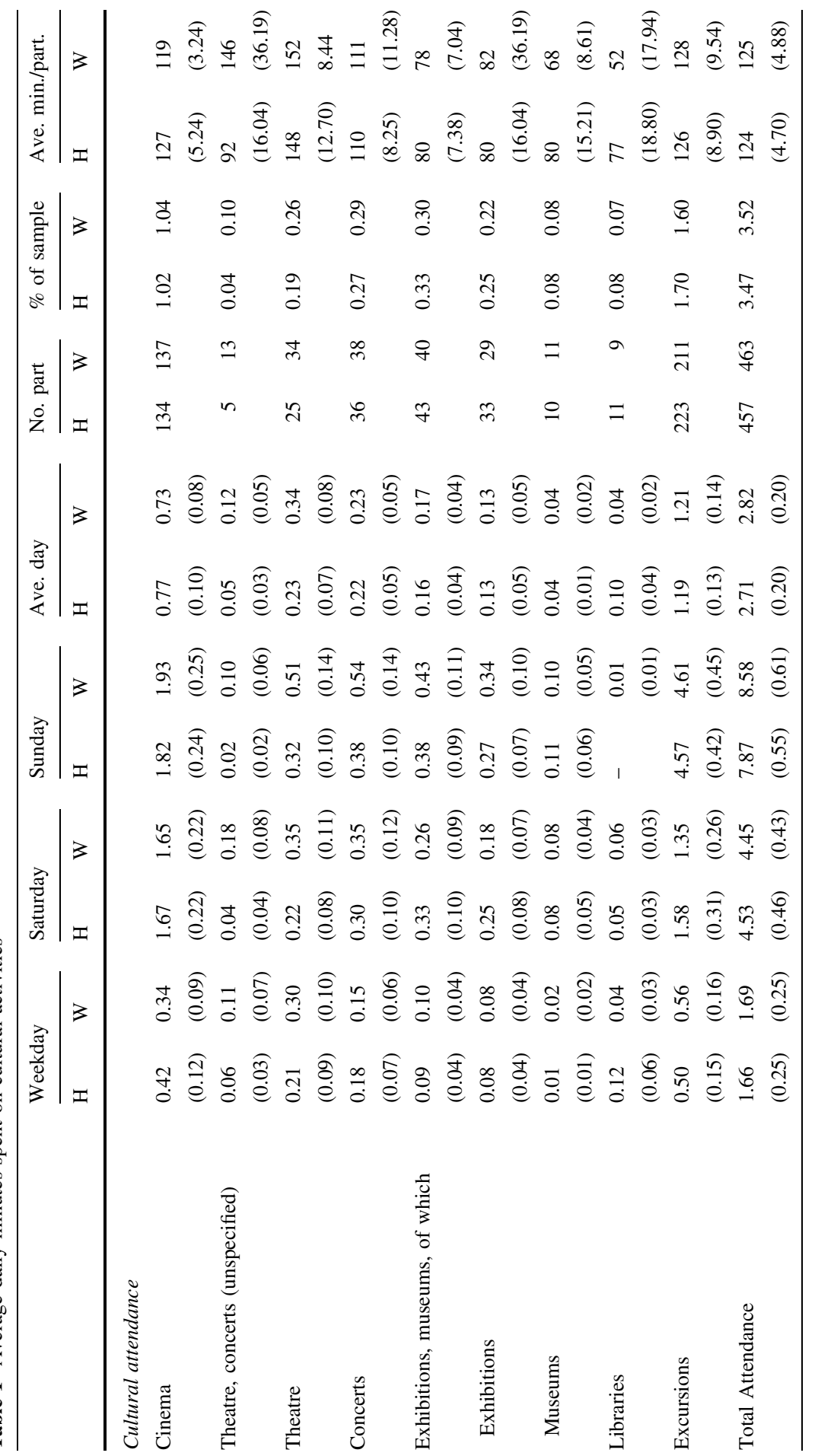




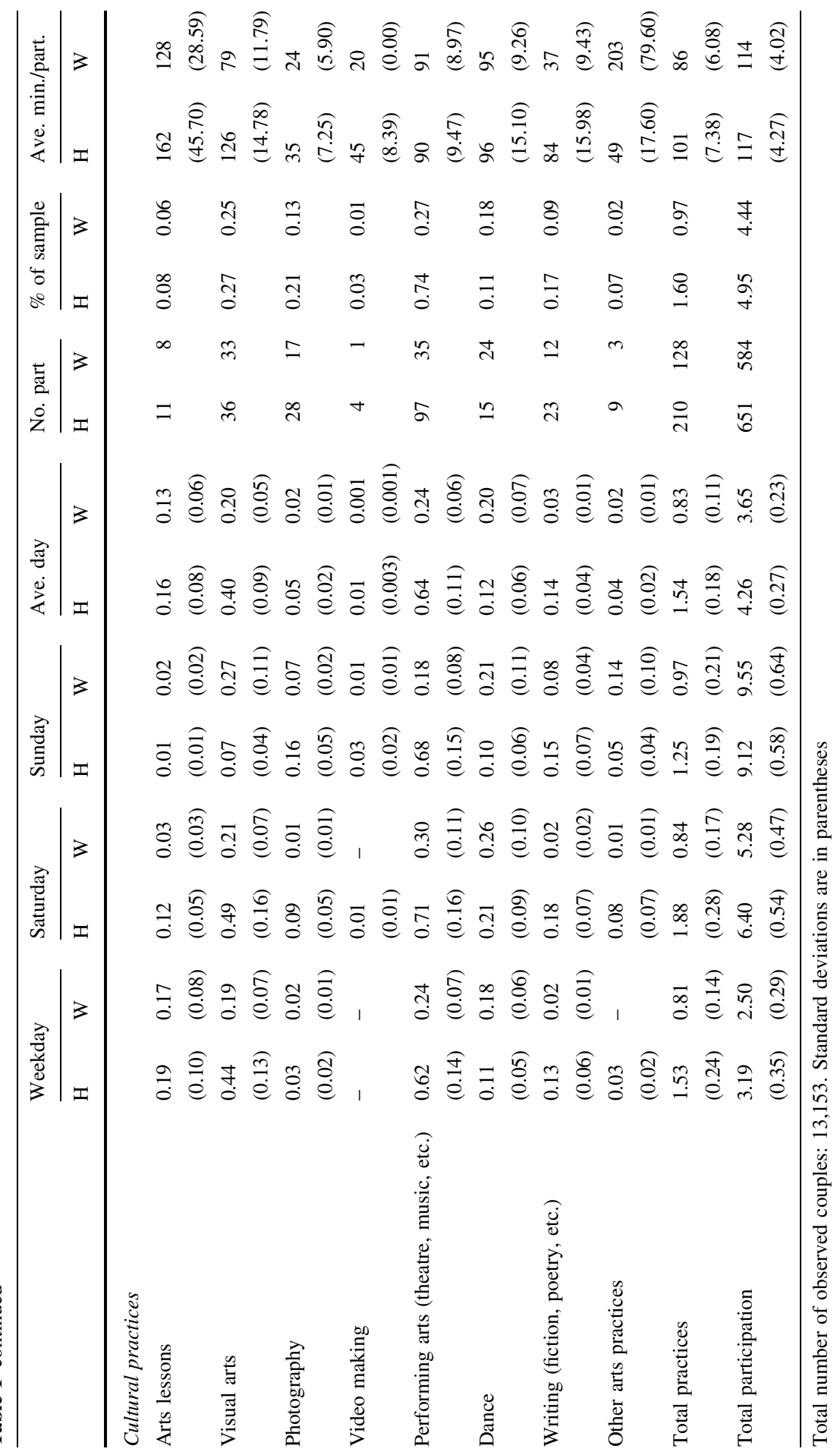


on average in arts attendance and practices in a day, i.e. less than $0.35 \%{ }^{4}$ Time spent in the arts doubles to almost $10 \mathrm{~min}$ on Sundays and decreases to about $3 \mathrm{~min}$ on a weekday. These low average durations are mainly due to a low proportion (almost $5 \%$, see column '\% of sample') of couples actually participating in culture. ${ }^{5}$ Nevertheless, we do notice a quite high average time allocated to culture (overall almost $2 \mathrm{~h}$ ) among actual participants (column 'Ave. min./part.').

On any given day during the week, arts attendance is given more time than arts practices, with differences peaking on weekends and especially on Sundays (from similar durations on a weekday to about eight times more for attendance with respect to practices). Interestingly, time spent on practices is much more regularly distributed during the week than in the case of attendance. Among cultural attendance, excursions prove to be the most time-intensive occupation, with averages ranging from half a minute to almost 5 min a day. They are followed by attendance at cinemas (less than half a minute to almost $2 \mathrm{~min}$ ), theatres and concerts, and museums and exhibitions (altogether). Time spent in libraries scores the lowest. Among cultural practices, music and theatre fetch the highest average time, followed by visual arts, dance, arts lessons, writing, photography and video making. In general, the group of actually participating people reflects the same rates of participation as the general public. Nevertheless, within this group, some activities attract relatively higher proportions of participants, together with lower average durations, such as attendance of exhibitions and museums, and concerts. The opposite holds for arts lessons and photography, among practices.

Husbands seem to spend more time on cultural participation altogether than wives $(+17 \%)$ and in particular on practices $(+86 \%$, up to $+124 \%$ on Saturdays with respect to wives), with the exception of dancing ( $+67 \%$ for wives compared to husbands). Nevertheless, the two genders spend similar amounts of time on attending cultural events, with some differences depending on the specific type of attendance, or part of the week. In particular, wives seem to attend concerts, and especially the theatre $(+39 \%)$, more than husbands, while the opposite holds for libraries, cinemas and excursions. In terms of weekly time distribution, on Sundays wives participate in the arts more than husbands, in particular in attendance $(+9 \%)$. This is remarkable, since men typically do more paid work than women, and therefore should profit relatively more of 'free' days such as weekends. Possible explanations for these differences between husbands and wives may include women's preferences for more social, lighter arts activities compared to more solitary, creative, effortful ones, as well as family burdens, such as taking care of children, typically relegated to wives in Italy, and their weekly distribution (Bloemen et al. 2010).

Given the differences in how husbands and wives allocate their time to cultural activities, it is of particular interest to look at how couples possibly synchronise in that respect. Figure 1 shows the proportion of time a husband and a wife spend simultaneously with their spouse on each cultural activity on an average weekday.

\footnotetext{
${ }^{4}$ Robinson and Godbey (1997) found that in the USA the overall time spent in the arts is below $0.30 \%$ of daily time, with movies representing the most popular arts activity $(0.20 \%)$ and museum and performing arts attendance scoring only $0.07 \%$ altogether. By adding sporting events, but excluding watching TV, it lies below $0.60 \%$.

5 Which is slightly less than summing up each activity, suggesting that a small proportion of individuals are involved in more than one cultural activity on the same day.
} 


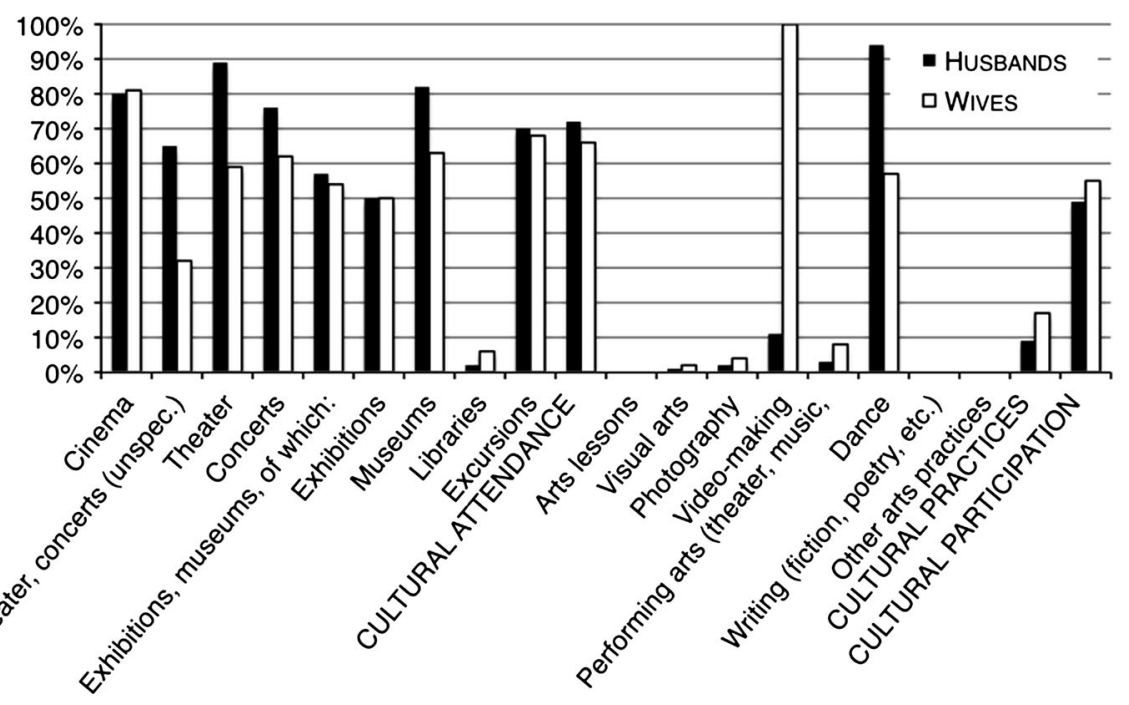

Fig. 1 Proportion of time spouses spend simultaneously on arts activities on an average day

Notice that Italian couples do about $50 \%$ of their cultural activities together. ${ }^{6}$ In particular, attending cultural events and venues (with the exception of libraries) brings couples together (almost $70 \%$ ), unlike arts practices (about $10 \%$, mainly on account of dancing). ${ }^{7}$

Table 2 presents the descriptive statistics when husbands and wives spend time in the arts, jointly and without their spouse. On average, spouses are younger when they participate in the arts together, with a lower difference in age between husbands and wives (49 and 45, vs 53 and 47). They both have a slightly higher educational level when they participate alone rather than together, and so do their respective spouses (with the exception of wives' education of husbands participating alone). Husbands and wives are more employed full-time when they participate together and they thus maximise the use of free time together. Similarly, joint participation is higher on weekends. The adequacy of the household's economic resources, which is in general below average for couples spending time in the arts, slightly decreases when spouses participate separately. On average, spouses involved in the arts present quite good health levels, especially if they do so together. In general, spouses' participation in the arts is lowered by the presence of children in the household (especially teenagers and young children), in particular when they have to coordinate to participate together (with the exception of children aged 6-13). On average, couples and, in particular, wives who are involved in the arts alone tend to live in central and northern Italy. Finally, joint participation is not favoured by the size of the municipality.

\footnotetext{
${ }^{6}$ For general leisure, Hallberg (2003) and Scheffel (2010) found, on average, weaker synchronization rates in, respectively, Swedish (about $45 \%$ ) and German (about $40 \%$ ) couples, and even lower togetherness rates (about $30 \%$ for German couples) (rough figures calculated from their data).

7 Notice also that, in the sample, when a given individual spent time in a given arts activity with his/her spouse, he/she was not involved in another arts activity alone.
} 
Table 2 Descriptive statistics of husbands and wives participating in arts together and alone

\begin{tabular}{|c|c|c|c|c|}
\hline \multirow[t]{2}{*}{ Averages (Std. deviations in parentheses) } & \multicolumn{2}{|l|}{ Joint } & \multicolumn{2}{|c|}{ Without spouse } \\
\hline & Husbands & Wives & Husbands & Wives \\
\hline AGE & $\begin{array}{l}48.564 \\
(11.85)\end{array}$ & $\begin{array}{l}45.022 \\
(11.57)\end{array}$ & $\begin{array}{l}52.580 \\
(13.52)\end{array}$ & $\begin{array}{l}47.262 \\
(11.40)\end{array}$ \\
\hline HUSBAND'S EDUCATION (Low 1, Medium 2, High 3) & $\begin{array}{l}1.696 \\
(0.68)\end{array}$ & & $\begin{array}{l}1.748 \\
(0.74)\end{array}$ & $\begin{array}{l}1.764 \\
(0.75)\end{array}$ \\
\hline WIFE'S EDUCATION (Low 1, Medium 2, High 3) & $\begin{array}{l}1.721 \\
(0.72)\end{array}$ & & $\begin{array}{l}1.657 \\
(0.72)\end{array}$ & $\begin{array}{l}1.764 \\
(0.71)\end{array}$ \\
\hline $\begin{array}{l}\text { HUSBAND'S WORKING-TIME REGIME (Not occupied 1, } \\
\text { Part-time 2, Full-time 3) }\end{array}$ & $\begin{array}{l}2.562 \\
(0.82)\end{array}$ & & $\begin{array}{l}2.203 \\
(0.96)\end{array}$ & $\begin{array}{l}2.484 \\
(0.87)\end{array}$ \\
\hline $\begin{array}{l}\text { WIFE'S WORKING-TIME REGIME (Not occupied 1, } \\
\text { Part-time 2, Full-time 3) }\end{array}$ & $\begin{array}{l}1.912 \\
(0.93)\end{array}$ & & $\begin{array}{l}1.783 \\
(0.91)\end{array}$ & $\begin{array}{l}1.853 \\
(0.94)\end{array}$ \\
\hline HUSBAND'S HEALTH (Low 1, Medium 2, High 3) & $\begin{array}{l}2.693 \\
(0.47)\end{array}$ & & $\begin{array}{l}2.542 \\
(0.57)\end{array}$ & $\begin{array}{l}2.631 \\
(0.51)\end{array}$ \\
\hline WIFE'S HEALTH (Low 1, Medium 2, High 3) & $\begin{array}{l}2.666 \\
(0.50)\end{array}$ & & $\begin{array}{l}2.251 \\
(0.55)\end{array}$ & $\begin{array}{l}2.587 \\
(0.54)\end{array}$ \\
\hline $\begin{array}{l}\text { SATISFACTION W/TOT. HOUSEHOLD } \\
\text { EC. RESOURCES (Scarce 1, Average 2, Optimal 3) }\end{array}$ & $\begin{array}{l}1.921 \\
(0.40)\end{array}$ & & $\begin{array}{l}1.916 \\
(0.38)\end{array}$ & $\begin{array}{l}1.867 \\
(0.40)\end{array}$ \\
\hline $\begin{array}{l}\text { HUSBAND'S SELF-ASSESSED LEVEL OF COUPLE } \\
\text { SATISFACTION (Low 1, Medium 2, High 3) }\end{array}$ & $\begin{array}{l}2.293 \\
(0.54)\end{array}$ & & $\begin{array}{l}2.273 \\
(0.59)\end{array}$ & $\begin{array}{l}2.168 \\
(0.60)\end{array}$ \\
\hline $\begin{array}{l}\text { WIFE'S SELF-ASSESSED LEVEL OF COUPLE } \\
\text { SATISFACTION (Low 1, Medium 2, High 3) }\end{array}$ & $\begin{array}{l}2.282 \\
(0.56)\end{array}$ & & $\begin{array}{l}2.168 \\
(0.60)\end{array}$ & $\begin{array}{l}2.222 \\
(0.61)\end{array}$ \\
\hline \multicolumn{5}{|l|}{ PRESENCE OF CHILDREN IN THE HOUSEHOLD } \\
\hline Aged $<6$ & $\begin{array}{l}0.145 \\
(0.35)\end{array}$ & & $\begin{array}{l}0.154 \\
(0.36)\end{array}$ & $\begin{array}{l}0.160 \\
(0.37)\end{array}$ \\
\hline Aged 6-13 & $\begin{array}{l}0.255 \\
(0.44)\end{array}$ & & $\begin{array}{l}0.217 \\
(0.41)\end{array}$ & $\begin{array}{l}0.236 \\
(0.43)\end{array}$ \\
\hline Aged 14-17 & $\begin{array}{l}0.099 \\
(0.30)\end{array}$ & & $\begin{array}{l}0.140 \\
(0.35)\end{array}$ & $\begin{array}{l}0.133 \\
(0.34)\end{array}$ \\
\hline Aged $>17$ & $\begin{array}{l}0.343 \\
(0.48)\end{array}$ & & $\begin{array}{l}0.402 \\
(0.49)\end{array}$ & $\begin{array}{l}0.373 \\
(0.49)\end{array}$ \\
\hline $\begin{array}{l}\text { GEOGRAPHICAL AREA OF RESIDENCE (South 1, Centre 2, } \\
\text { North 3) }\end{array}$ & $\begin{array}{l}2.353 \\
(0.83)\end{array}$ & & $\begin{array}{l}2.315 \\
(0.86)\end{array}$ & $\begin{array}{l}2.378 \\
(0.81)\end{array}$ \\
\hline MUNICIPALITY SIZE (<50k 1, >50k 2 Metropolitan 3) & $\begin{array}{l}1.762 \\
(0.95)\end{array}$ & & $\begin{array}{l}1.661 \\
(0.92)\end{array}$ & $\begin{array}{l}1.733 \\
(0.93)\end{array}$ \\
\hline WEEKEND & $\begin{array}{l}0.880 \\
(0.33)\end{array}$ & & $\begin{array}{l}0.713 \\
(0.45)\end{array}$ & $\begin{array}{l}0.716 \\
(0.45)\end{array}$ \\
\hline
\end{tabular}

\section{The empirical model}

Our empirical model is based on a Beckerian theoretical framework, in which individuals simultaneously decide time allocation among different activities, including the arts. We model the time $T_{i}$ that a couple (jointly) or each partner (individually) $i$ allocates to the arts as: 


$$
T_{i j}=\beta X_{i j}+\varepsilon_{i j}
$$

Explanatory variables include the observed characteristics of the individual, his/her spouse, and the couple's household. $\varepsilon_{i}$ is an error term. As we also noticed from a descriptive analysis of our data set, people do not usually spend time on the arts every single day, unlike sleeping, eating or personal care, that is $T$ is observed only for arts-goers. This causes the presence of zeros for many individuals, which is not only the result of infrequency in random sampling, but also of participation choice.

Arts participation is characterised by heterogeneity in preferences and a selection bias, since only those who choose to participate will have a positive probability of participating, unlike those who choose never to participate (e.g. Borgonovi 2004 for performing arts attendance; Boter et al. 2005 for travel time in museum attendance; Ateca-Amestoy 2008 for theatre attendance; Cornélio Diniz and Machado (2011) for the consumption of artistic-cultural goods and services; Fernández-Blanco et al. 2009; Grisolía and Willis, 2012).

Heckman's sample selection model (Gronau 1974; Lewis 1974; Heckman 1976) is a particularly appropriate econometric estimation method (see Lévy-Garboua and Montmarquette 1996 for a discussion of and application to theatre attendance; Urrutiaguer 2002 for an application to critics' scores in theatre reviews). In such a model, the equation above corresponds to the underlying regression relationship, where the dependent variable is not always observed. Rather, the dependent variable for observation $j$ is observed if (selection equation):

$$
Z_{i j} \gamma_{+} u_{i j}>0
$$

where the model assumes normal distribution with mean 0 of both error terms, the error terms are correlated, and the error terms are independent of respective explanatory variables:

$$
\begin{gathered}
\varepsilon \sim N(0, \sigma) \\
u \sim N(0,1) \\
\operatorname{corr}(\varepsilon, u)=\rho
\end{gathered}
$$

When $\rho$ is different from 0 , standard regression techniques applied to the first equation yield biased results. Heckman provides consistent, asymptotically efficient estimates for all the parameters in such models. The simplification of $\operatorname{Var}(u)=1$ normalises the variance of the error term in what will be a Probit regression.

In his study on trends in leisure and arts time allocation in the USA, Robinson (2010: 3) reports how arts participation is 'severely underreported' or 'largely invisible in people's time diaries', due to their high degree of variety and due to detail required in reporting them. For this reason, the dependent variable, time spent on different arts activities, was aggregated into the time spent on two main categories, overall arts participation, and its main component, arts attendance.

Following previous studies on arts participation (e.g. Borgonovi 2004; KatzGerro 2004; Seaman 2006), we expect age and educational attainment to play a significant role on both the decision to participate and the time allocated to the arts. In particular, we expect a positive relation between time spent in the arts and age, 
due to addiction and human capital (Stigler and Becker 1977) and learning by consuming (McCain 1979, 1986, 1995), with a possible concave relation of age (e.g. Robinson and Godbey 1997). We also expect a positive relationship with educational attainment (e.g. Aguiar and Hurst 2007, 2009; Hallberg 2003; Robinson 2010; Robinson and Godbey 1997). Levels of education in the Italian system include low (secondary school or below, 8 or fewer years of education completed), medium (high school, at least 13 years completed) and high (university, graduate or postgraduate, more than 13 years).

Spouses are assumed to influence each other endogenously in their preferences and characteristics, in particular through educational attainment and age (e.g. Benham 1974; van Berkel and De Graaf 1995; Upright 2004; Connelly and Kimmel 2009; Frateschi and Lazzaro 2008). However, we expect husbands and wives to have different respective influences (e.g. Upright 2004; Bloemen et al. 2010; Hendriks Vettehen and Konig 2012).

Our data do not contain information on individual income. We proxied it by including as regressors in the underlying regression equation the dummies being in the labour force (taking into account work income), and the declared level of satisfaction with the household total disposal of economic resources (taking into account also property income).

Kraaykamp et al. (2008) found that Dutch couples' time restrictions affected the frequency of their arts attendance (at both individual and joint level). In particular, with respect to full-time occupation, part-time working men seemed to increase their own arts attendance and that of their wives. This no longer held for women, which the authors related to the presence of children. Given the more traditional nature of Italian society, we expect similar but stronger evidence of this. Notice that, to avoid endogeneity, we do not include the individual's own working time regime in the underlying regression equation. However, for sake of time-coordination analysis between spouses, in the particular case of individual time spent on the arts we do control for the spouse's working time regime, with expected possible opposite effects on time spent on the arts. In the selection equation, we control for both spouses' working time regimes. Sullivan (1996), Hamermesh (2000) and Hallberg (2003) found that spouses tend to coordinate to enjoy leisure activities together. ${ }^{8}$ As suggested by Hallberg (2003), highly productive individuals (characterised by high educational levels) may coordinate either more with their

\footnotetext{
${ }^{8}$ Even if this is explained as a result of the general organisation of society, rather than of preferences for simultaneity or togetherness. Hamermesh's approach, followed, among others, by Hallberg (2003), Jenkins and Osberg (2005), van Klaveren and van den Brink (2007) and Scheffel (2010), is based on matched pseudo-couples. Through this approach, active synchronisation is disentangled from passive synchronisation, where the former is the result of preferences for coordination, and the latter of constraints imposed by the general organisation of society. Notice that in those studies the overall organisation of time is considered in few aggregate activities of market and house work, personal and family care, and leisure. Given, instead, the original degree of disaggregation of activities in our sample, and the implied correspondence between simultaneity and togetherness explained in the previous section, we assume that joint time in the arts is the result of preferences for coordination.
} 
spouses, because of better planning habits, or less, because of the trade-off between more activities. ${ }^{9}$

Other conditions being equal, good health should increase the amount of time dedicated to arts occupations overall, with additional positive reciprocal effects between spouses.

Happy couples should spend more time together in the arts. Joint cultural participation should be positively associated with couples' well-being, in particular in terms of shared enjoyment (consumption) and relationship building (investment) (Jenkins and Osberg 2005; Connelly and Kimmel 2009).

The presence of young children in the household was found to have a negative impact on arts time (Robinson and Godbey 1997) and frequency (Kraaykamp et al. 2008), especially when combined with a full-time working household. The opposite held for mixed-work burdens (at least one spouse working part-time, in particular men). Joint leisure time is expected to be lowered by the presence of children (e.g. Hallberg 2003; Bloemen et al. 2010; Silva and Le Roux 2011). Yet cultural activities that can also be done together with children could favour cultural participation as an educational activity.

Weekends versus weekdays generally account for paid work burdens, in addition to opportunities in households' and couples' leisure coordination. Therefore, weekends should favour arts participation and in particular more collective arts attendance.

Only in the selection equation did we include geographical indicators to account for the supply of arts facilities, with expected possible opposite effects. While metropolitan areas are richer in arts supply, their residents may be affected by more time constraints and substitutes, which may reduce their participation. Northern and central regions are relatively richer in cultural services than southern regions; therefore, spouses living there should participate more.

We finally expect some differences in the explanatory power of the above socioeconomic characteristics, between joint participation and individual participation, besides arts participation and arts attendance. These might be due to different timing, flexibility and coordination of arts activities, gender/spousal roles, and social and consumption patterns.

\section{Results}

Table 3 displays the main results for overall arts participation. More specifically, it presents the determinants of husbands' and wives' joint time use (as a couple) as well as their total individual time use (with or without the spouse) in arts

\footnotetext{
${ }^{9}$ Goodin et al. (2005) distinguished between free time and discretionary time. Free time is the residual time after 'obligatory' activities such as paid work, unpaid work and personal care. Discretionary time is the residual time after the minimum necessary time for those obligatory activities. Goodin et al. (2005) also define minimum necessary paid work. Following, among others, Robinson and Godbey (1997) Bittman and Wajcman (2000), Mattingly and Sayer (2006) and Craig (2007), Gimenez-Nadal and SevillaSanz (2011) included in the regressors the dummies working part- and full-time to study the leisure time of mothers and fathers (MTUS data), finding a significantly negative effect of full-time.
} 


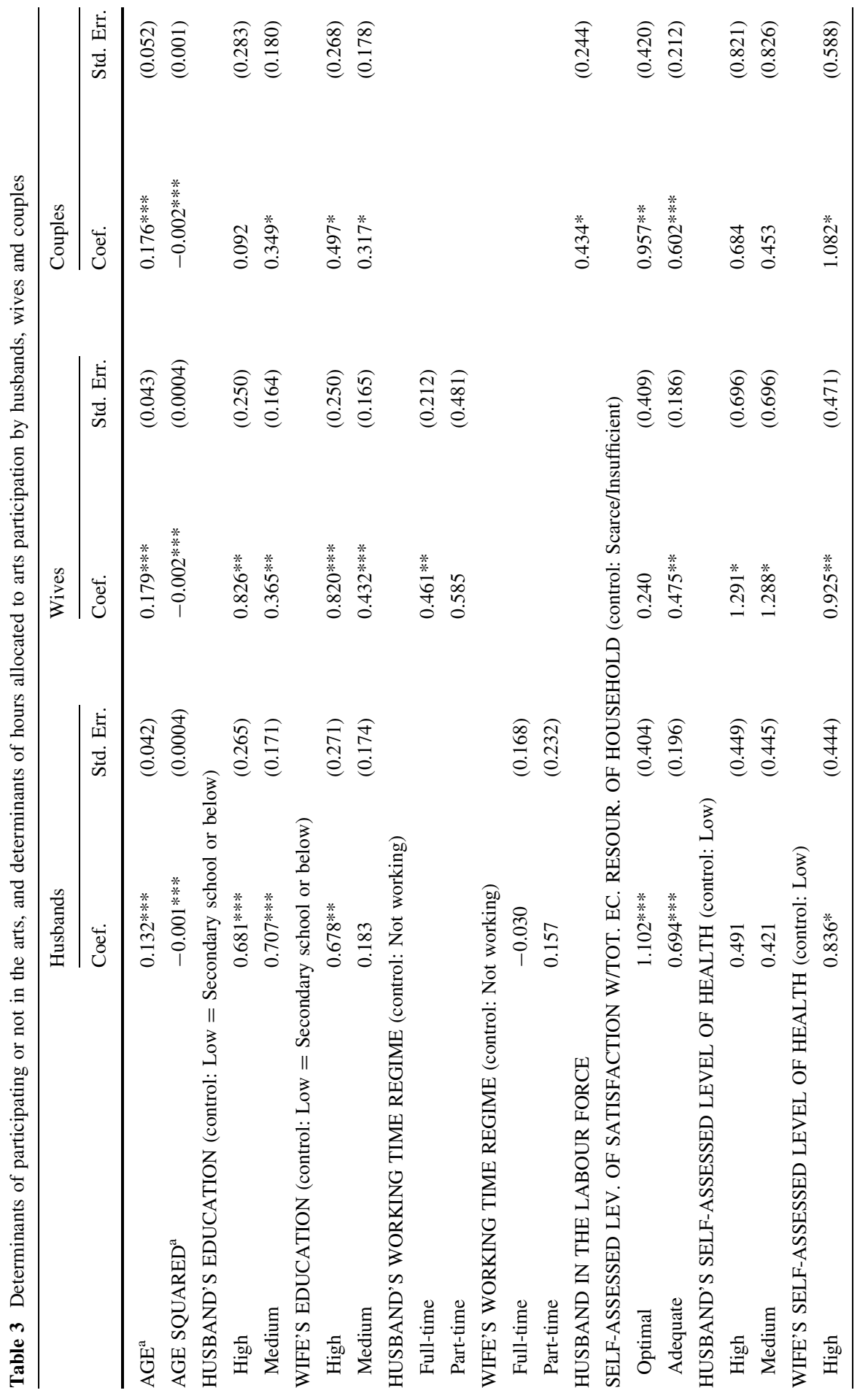




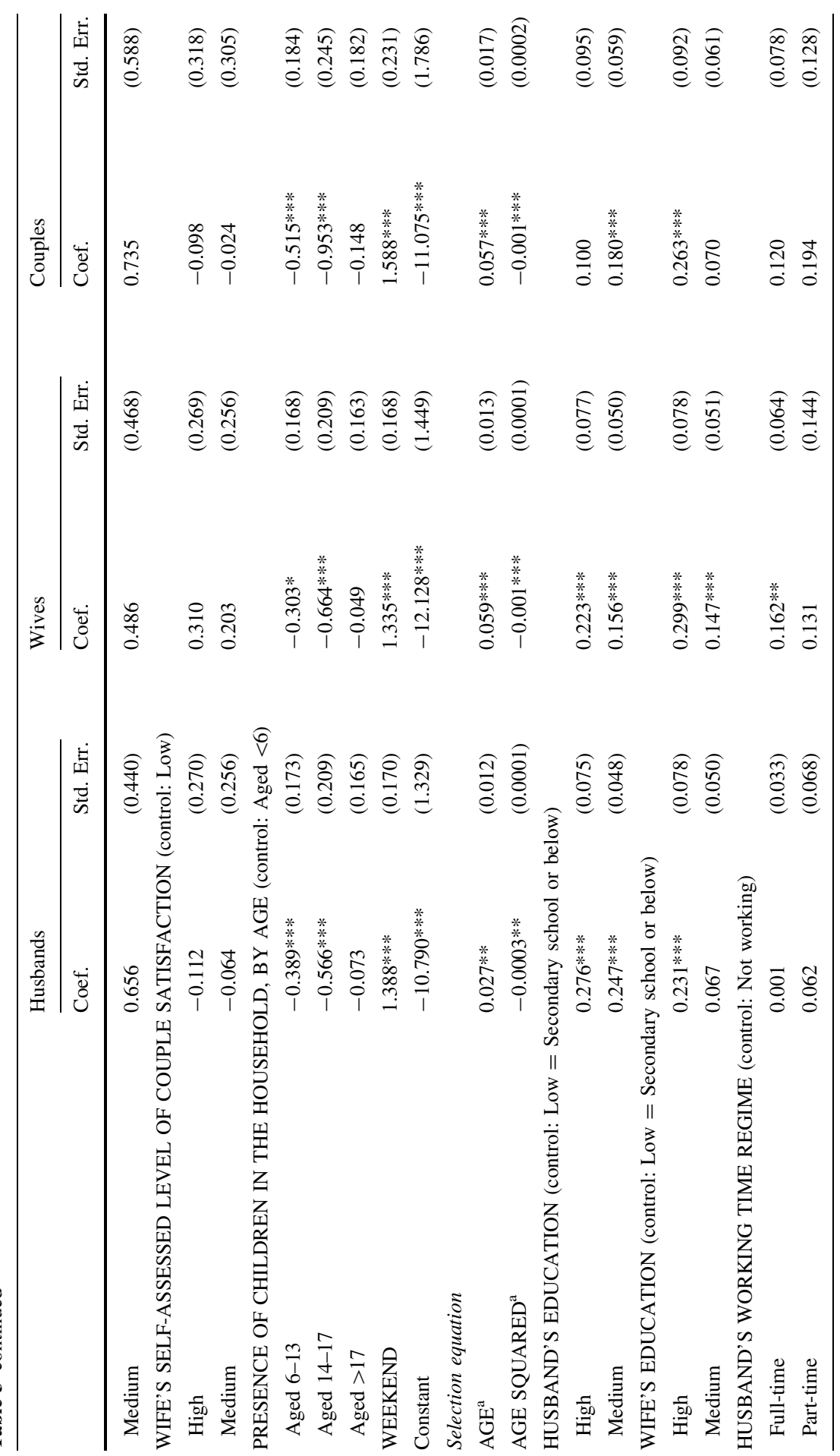




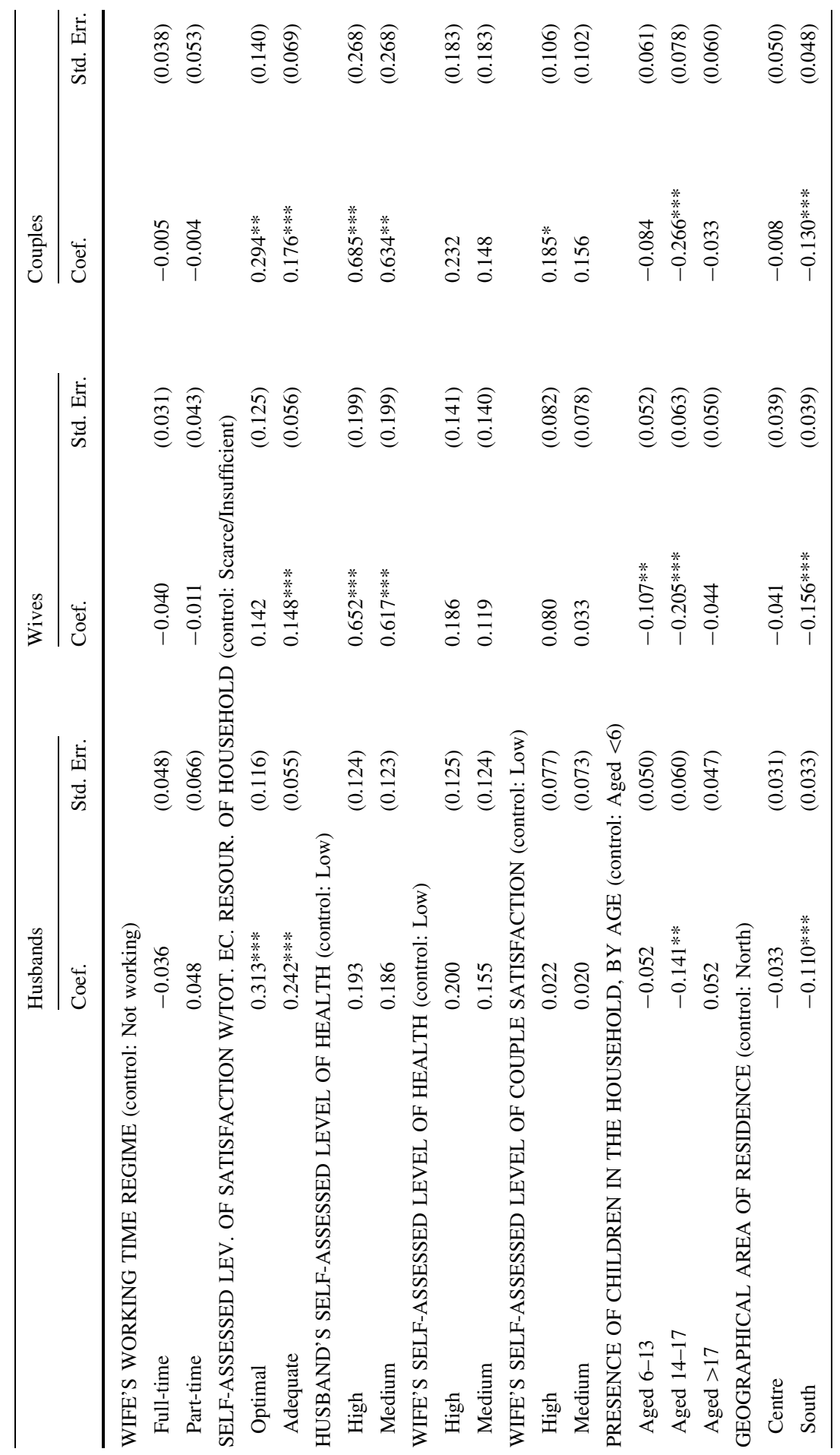




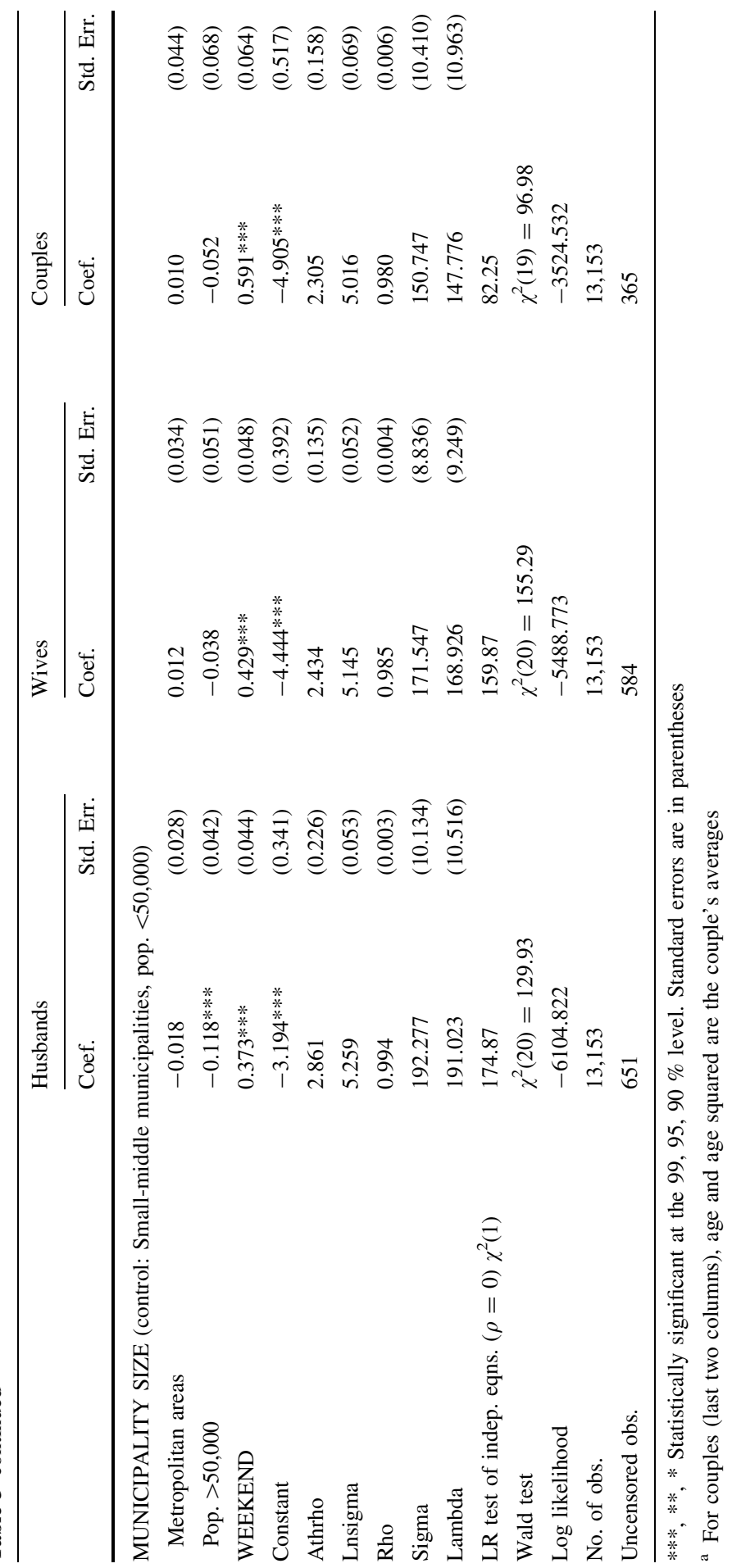


participation (attendance and practices). In the lower part of the table (below 'selection equation'), the Probit estimates for observing a nonzero amount of time on arts activities are shown.

Age is positively associated with the probability and the amount of time spent on joint and individual arts activities, which generally confirms previous results. By including age squared, joint time use reaches a peak at the age of 49 , which confirms the averages shown in Table 2, which is just a couple of years later. For both husbands' and wives' total participation, the top is 50, which is in line with husbands' averages, and slightly later for wives, who allocate time to the arts slightly longer in their lives, regardless of their companions. Peaks are lower for husbands' participation (45) and especially for wives' and joint participation (29). Even after we control for labour, family burdens and health, the justification of some life cycle effects could apply, at least for some types of arts activities, such as certain performing arts (Borgonovi 2004) and popular art (Katsuura 2008), which would reshape linear increasing effects of cultural and social capital and learning by consuming of other arts activities.

Spouses' levels of education have a positive impact on arts participation and the time allocated to it, as has been shown in earlier findings. Remarkably, the highest levels of education for wives correspond to more arts participation (e.g. Upright 2004) and more time allocated by both spouses, individually and jointly. For husbands, however, this is not evident for joint participation, joint allocated time and individual time. For men, medium levels of education have a relatively stronger impact, which confirms the different influences of men and women on arts choice (Hendriks Vettehen and Konig 2012). The influence of spouses' educational level is relatively stronger with individual time, rather than with joint time, and this influence is also reciprocal. Overall, women play a relatively more important social role than men in the engagement of couples in the arts.

When the husband is in the labour force, couple's joint participation and time use increase, suggesting economic but also rewarding and coordination considerations. Concerning individual participation, women married to men who are employed full-time (61\% of the sample) participate in and allocate more time to the arts than those married to men who are employed part-time or unemployed. This evidence contradicts previous findings about men in Dutch couples and the frequency of participation, but not about women (Kraaykamp et al. 2008). In fact, women's working time (61\% of the sample were not employed) has no impact on men's arts participation. Even if working partners have less available free time, our results confirm previous findings on the importance of income in arts participation (Seaman 2006; Cornélio Diniz and Machado 2011). Additional impact of income is taken into account by the self-assessed level of satisfaction with the total economic resources of the household, which at the highest levels increases the probability and the amount of time dedicated to arts participation by couples, as well by husbands. Noticeably, in the wealthiest households, other conditions being equal, wives participate or spend time on the arts less than in households of average wealth.

Results prove the importance of health in arts participation and in particular in time allocated to arts activities. More specifically, spouses' good health conditions 
favour each other's and joint arts engagement, with different roles played by the spouses, as has been shown in studies on leisure (Gimenez-Nadal and Sevilla-Sanz 2010). Noticeably, only husbands in optimal or adequate health conditions are positively associated with arts participation of wives and couples, besides wives' time spent in the arts. Conversely, the highest levels of health for wives are related only to overall time spent on the arts.

Highest levels of couple satisfaction confirm the expectations of increased probability of joint arts participation, as is the case with leisure (van Klaveren and van den Brink 2007). Curiously, this has no particular impact on the amount of time allocated by partners.

Compared to babies and small children, the presence of teenagers and younger children in the household negatively impacts the probability of spouses' individual and joint participation, contrary to previous findings on arts participation (Kraaykamp et al. 2008). The overall amount of time is also the most negatively impacted by this age group of children, followed by those aged 6-13. These results differ from previous findings for leisure time, where small children negatively impact parents' joint time (Hallberg 2003). The negative sign might imply a possible involvement of parents in leisure activities with children, in particular with teenage children, other than culture, such as sports and shopping. More interestingly, in terms of social interactions and the arts, it might imply some separation of roles in the family and thus separate arts participation, possibly with household children as alternative companions to partners.

As expected, the weekend is by far the preferred time of the week for arts participation and allocated time, which confirms general results for Italian couples (Bloemen et al. 2010). While wives are more likely to participate, husbands spend relatively more time on these activities during this part of the week.

With regard to the likelihood of participation, metropolitan areas, richer in arts supply, do not seem to differ from small to medium municipalities, while medium to large municipalities register less participation by couples, which suggests a 'provincial' effect. Central Italy is not significantly different from the north in spouses' joint and individual arts participation, while in southern Italy wives and couples participate less. This may be due to a combination of factors: a larger supply of arts activities in central and northern Italy, and differences in sociocultural habits.

When we estimated the equation using only arts attendance (results not shown), we obtained similar results. Some relative differences relate to a different impact of spouses' age (stronger), educational attainment (weaker for men only), working time regime (weaker) health (stronger and with different gender roles), couple's satisfaction and city size (no effect) and weekends (stronger).

\section{Conclusions}

In this paper, we analysed joint and individual arts participation and in particular time use of Italian couples. Time use data made available in the Time Use Survey of Italian households (ISTAT 2002-2003) were used for the first time for this purpose. Italian couples dedicate a small fraction of their day to arts participation, generally 
preferring arts attendance to arts practices. Nevertheless, their average time allocation for the arts is higher than other national averages. Not surprisingly, given the particularly unbalanced division of paid and unpaid work in this country and women's reduced access to leisure, we found that Italian husbands participate more and allocate more time to arts activities and practices than do their wives. However, these gender differences are relatively lower in arts time use than in work time use, confirming the general predisposition of women towards arts engagement. We also showed the existence of a variety of gender patterns in engaging individually or jointly the different arts, and the distribution of time intensity during the week. Remarkably, Italian couples turned out to spend together half of the time they dedicated to cultural activities, which suggests the importance of arts activities as moments of social interaction, reward and coordination.

Within a theoretical framework of household production, we disentangled the personal and mutual influence of partners' socio-economic characteristics on individual and joint arts participation and allocated time. Household characteristics were also controlled for. By applying a Heckman's sample selection model to time use data, we obtained results generally in line with previous findings about arts participation obtained with retrospective-surveys data. Our results also confirmed the presence of gender patterns and roles in arts participation and time use, patterns and roles sometimes different from other countries that have been studied. The engagement in the arts proved to be the effect of cultural capital and learning by consuming, even if influenced by life cycle effects. Education was confirmed to have a strong positive effect, with a key role played by wives with the highest levels of education; women have a stronger social role than men in the engagement of couples in the arts.

The positive effects of males' working conditions suggested the relevance of economic factors but also coordination effects within couples. The latter could be the object of more specific research, in particular in relation to respective gender roles. Similarly, the presence of children in the household suggested alternative roles in the family in terms of arts companionship, which could be also interesting to study further.

Our results highlighted the positive effects of subjective well-being indicators on arts participation and time use, such as partners' health and couple satisfaction, in line with more general findings on leisure. This suggests the important relation between well-being and cultural activities and practices.

Remarkably, the same studied couples showed that the likelihood to participate in the arts and the amount of time allocated to them are determined by different causes. In general, time use analysis proved to be a valid complement to the study of arts participation.

Acknowledgments The authors would like to thank the editor Kathryn Graddy, two anonymous referees, Jonathan Gershuny, John Robinson, Olivier Donni, Elena Stancanelli, Elsa Fontainha, Elizabeth Amann and Kimberly Fisher for helpful comments and discussions. All errors are the sole responsibility of the authors. 
Open Access This article is distributed under the terms of the Creative Commons Attribution 4.0 International License (http://creativecommons.org/licenses/by/4.0/), which permits unrestricted use, distribution, and reproduction in any medium, provided you give appropriate credit to the original author(s) and the source, provide a link to the Creative Commons license, and indicate if changes were made.

\section{References}

Aguiar, M., \& Hurst, E. (2007). Measuring trends in leisure: The allocation of time over three decades. The Quarterly Journal of Economics, 122, 969-1006.

Aguiar, M., \& Hurst, E. (2009). A summary of trends in American time allocation: 1965-2005. Social Indicators Research, 93, 57-64.

Ateca-Amestoy, V. (2008). Determining heterogeneous behavior for theater attendance. Journal of Cultural Economics, 32, 127-151.

Beblo, M. (2001). The leisure gap between working parents. In Bargaining over time allocation (pp. 99-115). Physica-Verlag HD.

Becker, G. S. (1965). A theory of allocation of time. The Economic Journal, 75, 493-517.

Benham, L. (1974). Benefits of women's education within marriage. In T. W. Schultz (Ed.), Economics of the family: Marriage, children, and human capital. Chicago: University of Chicago Press.

Bittman, M., \& Wajcman, J. (2000). The rush hour: The character of leisure time and gender equity. Social Forces, 79, 165-189.

Bloemen, H. G., Pasqua, S., \& Stancanelli, E. G. F. (2010). An empirical analysis of the time allocation of Italian couples: Are they responsive? Review of Economics of the Household, 8, 345-369.

Borgonovi, F. (2004). Performing arts attendance: An economic approach. Applied Economics, 36, $1871-1885$

Boter, J., Rouwendal, J., \& Wedel, M. (2005). Employing travel time to compare the value of competing cultural organizations. Journal of Cultural Economics, 29, 19-33.

Connelly, R., \& Kimmel, J. (2009). Spousal influences on parents' non-market time choices. Review of Economics of the Household, 7, 361-394.

Cornélio Diniz, S., \& Machado, A. F. (2011). Analysis of the consumption of artistic-cultural goods and services in Brazil. Journal of Cultural Economics, 35, 1-18.

Corneo, G. (2005). Work and television. European Journal of Political Economy, 21, 99-113.

Fernández-Blanco, V., Orea, L., \& Prieto-Rodriguez, J. (2009). Analyzing consumers heterogeneity and self-reported tastes: An approach consistent with the consumer's decision making process. Journal of Economic Psychology, 30, 622-633.

Frateschi, C., \& Lazzaro, E. (2008). Attendance to cultural events and spousal influences: The Italian case. Marco Fanno WP No. 84.

Gimenez-Nadal, J. I., \& Sevilla-Sanz, A. (2010). The time-crunch paradox. Social Indicators Research, 102, 181-196.

Goodin, R. E., Rice, J. M., Bittman, M., \& Saunders, P. (2005). The time-pressure illusion: Discretionary time vs free time. Social Indicators Research, 73, 43-70.

Grisolía, J. M., \& Willis, K. (2012). A latent class model for theatre demand. Journal of Cultural Economics, 36, 113-139.

Gronau, R. (1974). The effect of children on the housewife's value of time. In T. W. Schultz (Ed.), Economics of the family: Marriage, children, and human capital (pp. 457-490). Chicago: University of Chicago Press.

Hallberg, D. (2003). Synchronous leisure, jointness and household labor supply. Labour Economics, 10, 185-203.

Hamermesh, D. S. (2000). Togetherness: Spouses' synchronous leisure, and the impact of children. NBER WP No. 7455.

Heckman, J. J. (1976). The common structure of statistical models of truncation, sample selection and limited dependent variables and a simple estimator for such models. Annals of Economic and Social Measurement, 5, 475-492.

Hendriks Vettehen, P., \& Konig, R. P. (2012). Explaining television choices: The influence of parents and partners. Poetics, 40, 565-585.

Horn, R. V. (1983). Cultural statistics and indicators. Journal of Cultural Economics, 7, 25-40. 
Horowitz, H. (1981). The UNESCO framework for cultural statistics and a cultural data bank for Europe. Journal of Cultural Economics, 5, 1-17.

Horowitz, H. (1990). A panel discussion: Measuring changes in national cultural behavior patterns. Journal of Cultural Economics, 14, 1-17.

Jenkins, S. P., \& Osberg, L. (2005). Nobody to play with? The implications of leisure coordination. In D. S. Hamermesh \& G. A. Pfann (Eds.), The economics of time use (pp. 113-145). Amsterdam: Elsevier.

Juster, F. T., \& Stafford, F. P. (1991). The allocation of time: empirical findings, behavioral models, and problems of measurement. Journal of Economic Literature, 29, 471-522.

Katsuura, M. (2008). Examining arts participation in Japan using the survey on time use and leisure activities. Asia Pacific Journal of Arts \& Cultural Management, 5, 343-361.

Katz-Gerro, T. (2004). Cultural consumption research: Review of methodology, theory, and consequence. International Review of Sociology, 14, 1-19.

Konig, R. P., Kraaykamp, G., \& Westerik, K. (2008). Partners' influence on each other's television exposure: Dominance or symmetry? Communications, 33, 371-384.

Kraaykamp, G., van Eijck, K., Ultee, W., \& van Rees, K. (2007). Status and media use in the Netherlands. Do partners affect media tastes? Poetics, 35, 132-151.

Kraaykamp, G., van Gils, W., \& Ultee, W. (2008). Cultural participation and time restrictions: Explaining the frequency of individual and joint cultural visits. Poetics, 36, 316-332.

Lam, D. (1988). Marriage markets and assortative mating with household public goods. Journal of Human Resources, 23, 462-487.

Lévy-Garboua, L., \& Montmarquette, C. (1996). A microeconometric study of theater demand. Journal of Cultural Economics, 20, 25-50.

Lewis, H. G. (1974). Comments on selectivity biases in wage comparisons. Journal of Political Economy, $82,1145-1155$.

Mattingly, M. J., \& Sayer, L. C. (2006). Under pressure: Gender differences in the relationship between free time and feeling rushed. Journal of Marriage and Family, 68, 205-221.

McCain, R. A. (1979). Reflections on the cultivation of taste. Journal of Cultural Economics, 3, 30-52.

McCain, R. A. (1986). Game theory and cultivation of taste. Journal of Cultural Economics, 10, 1-16.

McCain, R. A. (1995). Cultivation of taste and bounded rationality: Some computer simulations. Journal of Cultural Economics, 19, 1-15.

Mencarini, L., \& Tanturri, M. L. (2004). Time use, family role-set and childbearing among Italian working women. Genus, LX, III.

Mohr, J., \& DiMaggio, P. (1995). The intergenerational transmission of cultural capital. Research in Social Stratification and Mobility, 14, 167-199.

Montgomery, S. S., \& Robinson, M. D. (2010). Empirical evidence of the effects of marriage on male and female attendance at sports and arts. Social Science Quarterly, 91, 99-116.

Robinson, J. P. (2010). Sex, arts and verbal abilities: Three further indicators of how American life is not improving. Social Indicators Research, 99, 1-12.

Robinson, J. P., \& Godbey, G. (1997). Time for life: The surprising ways Americans use their time. University Park: The Pennsylvania State University.

Robinson, J. P., \& Martin, S. (2009). Of time and television. Annals of the American Academy of Political and Social Science, 625, 74-86.

Scheffel, J. (2010). Honey, I'll Be Working Late Tonight: The Effect of Individual Work Routines on Leisure Time Synchronization of Couples. Humboldt-Universität Discussion Paper No. 2010-016.

Seaman, B. A. (2006). Empirical studies of demand for the performing arts. In V. Ginsburgh \& C. D. Throsby (Eds.), Handbook of the economics of art and culture (pp. 415-472). Amsterdam: Elsevier.

Silva, E. B., \& Le Roux, B. (2011). Cultural capital of couples: Tensions of elective affinities. Poetics, 39, $547-565$.

Stigler, G. J., \& Becker, G. S. (1977). De Gustibus Non Est Disputandum. American Economic Review, 67, 76-90.

Sullivan, O. (1996). The enjoyment of activities: Do couples affect each others' well-being? Social Indicators Research, 38, 81-102.

Sullivan, O. (2007). Cultural voraciousness-A new measure of the pace of 30 leisure in a context of 'harriedness'. International Journal of Time Use Research, 4, 30-46.

Upright, C. B. (2004). Social capital and cultural participation: Spousal influences on attendance at arts events. Poetics, 32, 129-143. 
Urrutiaguer, D. (2002). Quality judgements and demand for French public theatre. Journal of Cultural Economics, 26, 185-202.

van Berkel, M., \& De Graaf, N. D. (1995). Husband's and wife's culture participation and their levels of education: A case of male dominance? Acta Sociologica, 38, 131-149.

van Klaveren, C., \& van den Brink, H. M. (2007). Intra-household work time synchronization: Togetherness or material benefits? Social Indicators Research, 84, 39-52.

van Rees, K., \& van Eijck, K. (2003). Media repertoires of selective audiences: The impact of status, gender, and age on media use. Poetics, 31, 465-490.

Voorpostel, M., van der Lippe, T., \& Gershuny, J. (2009). Trends in free time with a partner: A transformation of intimacy? Social Indicators Research, 93, 165-169. 